\title{
The risk of oversizing with sutureless bioprosthesis in small aortic annulus
}

Jerome Baert, MD, Parla Astarci, MD, PhD, Philippe Noirhomme, MD, and

Laurent de Kerchove, MD, PhD, Brussels, Belgium

From the Division of Cardiovascular Surgery, Institut de Recherche Expérimentale et Cliniques, Université Catholique de Louvain, Cliniques Universitaires Saint-Luc, Brussels, Belgium.

Disclosures: Authors have nothing to disclose with regard to commercial support.

Received for publication Aug 10, 2016; revisions received Sept 9, 2016; accepted for publication Sept 16, 2016; available ahead of print Oct 15,2016

Address for reprints: Laurent de Kerchove, MD, $\mathrm{PhD}$, Division of Cardiothoracic and Vascular Surgery, Cliniques Universitaires Saint-Luc, Ave Hippocrate 10, 1200 Brussels, Belgium (E-mail: laurent. dekerchove@uclouvain.be).

J Thorac Cardiovasc Surg 2017;153:270-2

$0022-5223 / \$ 36.00$

Copyright (c) 2016 by The American Association for Thoracic Surgery

http://dx.doi.org/10.1016/j.jtcvs.2016.09.035

\section{TTCS

Video clip is available online.

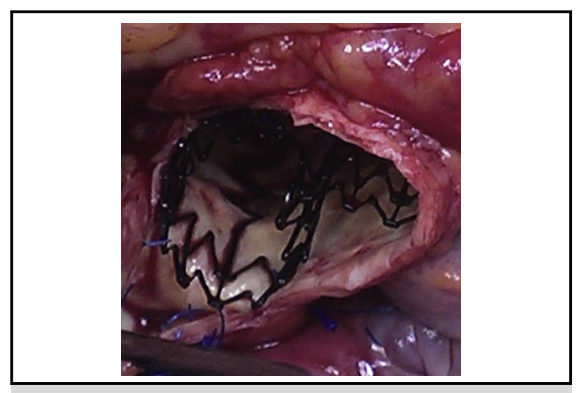

Typical intraoperative and transesophageal echography stent recoil with paravalvular leak.

Central Message

Oversizing of the Perceval S (Liva Nova PLC, London, United Kingdom) can occur, mainly in the small aortic annulus, and leads to paravalvular leak. Our experience shows that the sizing method should be improved in patients with a small aortic annulus.

See Editorial Commentary page 273.
The Perceval S (Liva Nova PLC, London, United Kingdom) sutureless bioprosthesis is a self-expanding bovine pericardial valve. Because of a simple and fast implantation technique, this valve allows a short crossclamp time with excellent hemodynamics and almost no paravalvular leak. ${ }^{1,2}$ The supplied sizers determine the best-suited prosthesis by measuring the aortic annulus after native valve resection. ${ }^{3}$ We report the case of 4 patients in whom incomplete deployment led to severe dysfunction and explantation of the Perceval S bioprosthesis.

\section{MATERIALS AND METHODS}

At the Cliniques Universitaires Saint-Luc, 136 patients (mean age, $79 \pm 6$ years; $58 \%$ were female) with severe aortic stenosis received the Perceval bioprosthesis from 2013 to 2016. Patients underwent operation by full $(60 \%)$ or partial $(40 \%)$ sternotomy. After a high transverse aortotomy ( $2 \mathrm{~cm}$ above the sinotubular junction [STJ]), the native leaflets were resected and the annulus was decalcified. According to the instructions for use, the prosthesis size was indicated by the sizer in which the transparent obturator passed through the annulus but the white obturator did not. ${ }^{3}$ When hesitating between 2 sizes, the smaller size was chosen. An annulus that was too small (when the transparent obturator of the small sizer does not pass the annulus) or too large (when the white obturator of the extra-large sizer passes the annulus) was a contraindication for implantation of the Perceval bioprosthesis. Small (annulus 19-21 mm), medium $(21-23 \mathrm{~mm})$, and large $(23-25 \mathrm{~mm})$ prosthesis sizes have been available since 2013 . The extra-large size $(25-27 \mathrm{~mm})$ has been available since 2014. After valve deployment, balloon dilatation was performed as recommended. Intraoperative transesophageal echocardiography (TEE) was systematically performed (Video 1).

\section{RESULTS}

In 4 patients $(2.9 \%)$ of our cohort, incomplete valve deployment with severe dysfunction occurred during

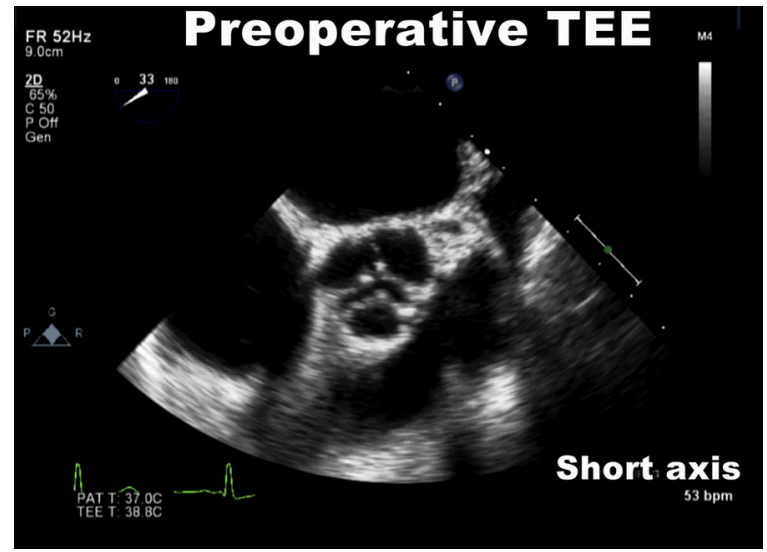

VIDEO 1. Intraoperative TEE. First part: Preoperative assessment of aortic valve stenosis. VAJ and STJ measurement: 20 and $19 \mathrm{~mm}$, respectively. Second part: Postimplantation TEE showing incomplete deployment of a small Perceval (Liva Nova PLC, London, United Kingdom) bioprosthesis associated with a severe paravalvular leak at the level of the stent recoil. Third part: TEE after prosthesis replacement with Medtronic (Minneapolis, Minn) Freestyle root \#21. Video available at: http:// www.jtcvsonline.org/article/S0022-5223(16)31153-9/addons. 


\begin{tabular}{|c|c|c|c|c|c|c|c|c|}
\hline $\begin{array}{c}\text { Case } \\
\text { description }\end{array}$ & $\begin{array}{l}\text { TEE VAJ } \\
\text { size }(\mathrm{mm})\end{array}$ & $\begin{array}{l}\text { TEE STJ } \\
\text { size }(\mathbf{m m})\end{array}$ & Procedure & $\begin{array}{l}\text { Prosthesis } \\
\text { dysfunction }\end{array}$ & Management & $\begin{array}{l}\text { Aortic } \\
\text { crossclamp } \\
\text { time (min) }\end{array}$ & $\begin{array}{c}\text { TTE } \\
\text { discharge } \\
\text { (PG/MG) } \\
\text { (mm Hg) }\end{array}$ & $\begin{array}{l}\text { Status at } \\
\text { follow-up }\end{array}$ \\
\hline $\begin{array}{l}\text { Patient 1: } 76 \text { y } \\
\text { Redo } \\
\qquad \text { (MVR 1991) } \\
\text { AVS + TI }\end{array}$ & 21 & 20 & $\begin{array}{l}\text { Full sternotomy, } \\
\text { Perceval (Liva } \\
\text { Nova PLC, London, } \\
\text { United Kingdom) } \\
\text { medium, TV } \\
\text { annuloplasty }\end{array}$ & $\begin{array}{l}\text { TEE: severe } \\
\text { paravalvular leak, } \\
\text { recoil image }\end{array}$ & Perceval Small & 103 & $\begin{array}{l}\text { No AR } \\
19 / 5\end{array}$ & $\begin{array}{l}\text { Alive } \\
(7 \mathrm{mo})\end{array}$ \\
\hline $\begin{array}{l}\text { Patient 2: } 77 \mathrm{y} \\
\text { AVS }\end{array}$ & 19 & 19 & $\begin{array}{l}\text { Partial sternotomy, } \\
\text { Perceval small }\end{array}$ & $\begin{array}{l}\text { Incomplete } \\
\text { deployment on } \\
\text { visual inspection }\end{array}$ & $\begin{array}{l}\text { Full sternotomy, } \\
\text { Trifecta (St Jude } \\
\text { Medical, St Paul, } \\
\text { Minn) } 21 \mathrm{~mm}, \\
\text { aortic root } \\
\text { enlargement, } \\
\text { CABG (RCA) }\end{array}$ & 133 & $\begin{array}{l}\text { No AR } \\
29 / 16\end{array}$ & $\begin{array}{l}\text { Alive } \\
(3 \mathrm{mo})\end{array}$ \\
\hline $\begin{array}{l}\text { Patient 3: } 76 \text { y } \\
\text { AVS }\end{array}$ & 20 & 19 & $\begin{array}{l}\text { Partial sternotomy, } \\
\text { Perceval small }\end{array}$ & $\begin{array}{l}\text { TEE: severe } \\
\text { paravalvular leak, } \\
\text { recoil image }\end{array}$ & $\begin{array}{l}\text { Full sternotomy, } \\
\text { Freestyle } \\
\text { (Medtronic, } \\
\text { Minneapolis, Minn) } \\
\text { root } 21 \mathrm{~mm}, \mathrm{CABG} \\
\text { (RCA) }\end{array}$ & 136 & $\begin{array}{l}\text { No AR } \\
15 / 7\end{array}$ & $\begin{array}{l}\text { Alive } \\
(6 \mathrm{mo})\end{array}$ \\
\hline $\begin{array}{l}\text { Patient } 4: 76 \text { y } \\
\text { AVS + CAD }\end{array}$ & 20 & 20 & $\begin{array}{l}\text { Full sternotomy, } \\
\text { Perceval medium, } \\
\text { CABG }\end{array}$ & $\begin{array}{l}\text { TEE: severe } \\
\text { paravalvular leak, } \\
\text { recoil image }\end{array}$ & Perceval Small & 112 & $\begin{array}{l}\text { No AR } \\
32 / 16\end{array}$ & $\begin{array}{l}\text { Alive } \\
(8 \mathrm{mo})\end{array}$ \\
\hline
\end{tabular}

$\overline{T E E}$, Transesophageal echocardiography; VAJ, ventriculo-aortic junction; $S T J$, sinotubular junction; TTE, transthoracic echography; $P G$, peak gradient; $M G$, mean gradient; $M V R$, mitral valve replacement; $A V S$, aortic valve stenosis; $T I$, tricuspid insufficiency; $T V$, tricuspid valve; $A R$, aortic regurgitation; $C A B G$, coronary artery bypass grafting; $R C A$, right coronary artery; $C A D$, coronary artery disease.

surgery and led to explantation of the prosthesis. These patients underwent operations by 2 senior surgeons (P.N., $\mathrm{n}=2$; L.dK., $\mathrm{n}=2$ ), who performed 59 and 43 Perceval implantations, respectively, before this complication occurred. Table 1 summarizes the relevant characteristics and outcomes of the 4 patients. The annular size measured on intraoperative TEE ranged from 19 to $21 \mathrm{~mm}$. In all cases, the ratio of the STJ to annulus was less than 1.3 , as recommended by the instructions for use. The sizing performed with the dedicated obturator indicated that the aortic annulus was best for a small $(n=2)$ or medium $(n=2)$ prosthesis size. Nonlabeled use of the Perceval was performed in $1 \mathrm{pa}-$ tient who previously received a mechanical mitral valve. The feasibility of Perceval implantation in this context has been reported by Minh and colleagues. ${ }^{4}$

In a 77-year-old patient (Patient 2; Table 1), the stent recoil occurred directly and spontaneously after balloon dilatation (Figure 1, A). In the 3 other patients (patients 1, 3 , and 4), the valve was correctly deployed and positioned, but stent recoil occurred after the aorta was closed and the complication was observed only during postimplant TEE. No particularly aggressive manipulation of the aorta occurred before the complication was observed. In the 3 patients, TEE showed incomplete prosthesis deployment associated with a severe paravalvular leak at the level of the stent recoil (Figure 1,
$B-D)$. Stent recoil generally was observed at the level of the noncoronary sinus. In patients initially receiving a medium-sized valve (patients 1 and 4), this was successfully replaced by a small-sized valve $(n=2)$. In those initially receiving a small valve (patients 2 and 3 ), the valve was replaced by another bioprosthesis $(n=2)$ associated with root enlargement or replacement (Table 1). The postoperative course was uneventful for all patients, and discharge transthoracic echocardiography showed normal prosthesis function with no paravalvular leak and low transvalvular gradient. All patients were alive at 7, 3, 6, and 8 months, respectively.

\section{DISCUSSION}

Inappropriate valve sizing and malposition have been reported to cause paravalvular leakage. ${ }^{5}$ However, incomplete valve deployment and stent recoil leading to severe dysfunction of the Perceval bioprosthesis have never been reported in the literature. We believe the mechanism of valve dysfunction we describe is related to oversizing rather than to malposition. In case of malposition, the valve generally is well deployed, but the inflow ring is misplaced below or above the annulus. In our cases, the inflow ring remained at the level of the annulus, but stent recoil induced loss of contact between the prosthesis and the aortic root from the annulus to STJ. Unpublished in vitro testing 

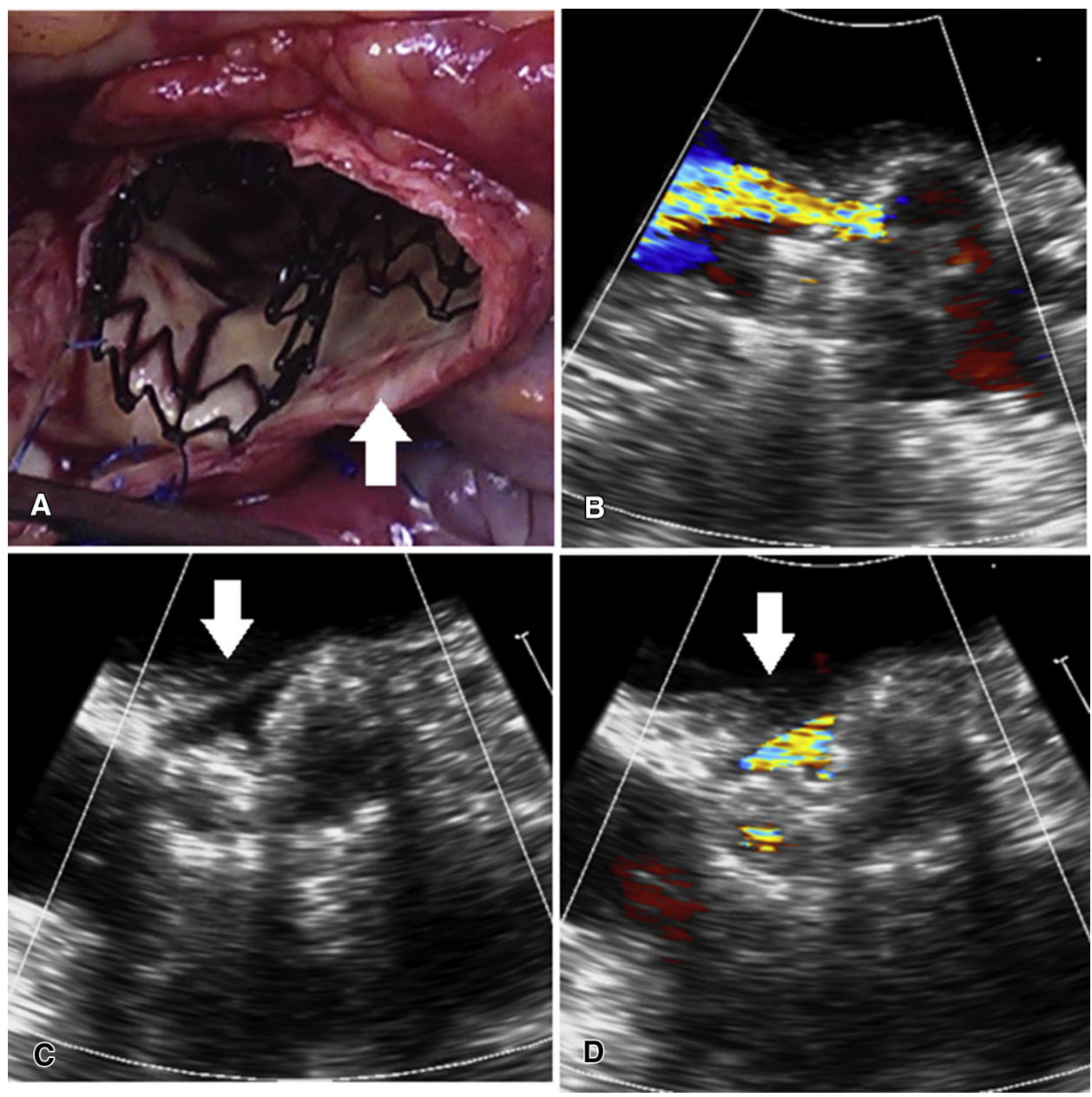

FIGURE 1. A, Intraoperative picture. B-D, Postimplant TEE. B, Short-axis view. C, Short-axis view with color Doppler. D, Long-axis view with color Doppler.

performed by Liva Nova PLC confirms that experimental oversizing of the prosthesis induces similar deformation (unpublished data, April 2016). Also, Liva Nova PLC recognized that similar cases occasionally have been reported to them, and they are currently working on a more objective and accurate sizing method.

\section{CONCLUSIONS}

This case report supports the recommendation of Liva Nova PLC to choose the smaller size when hesitating between 2 sizes. In addition, we recommend slightly modifying the actual sizing method, especially in the small annulus, and implanting the valve size given by the sizer when the white obturator passes the annulus with friction.

\section{References}

1. Laborde F, Fischlein T, Hakim-Meibody K, Misfeld M, Carrel T, Zembala M, et al. Cavalier Trial Investigators. Clinical and haemodynamic outcomes in 658 patients receiving the Perceval sutureless aortic valve: early results from a prospective European multicenter study (The Cavalier Trial). Eur J Cardiothorac Surg. 2016;49: 978-86.

2. Shrestha M, Fischlein T, Meuris B, Flameng W, Carrel T, Madonna F, et al. European multicenter experience with the sutureless Perceval valve: clinical and haemodynamic outcomes up to 5 years in over 700 patients. Eur J Cardiothorac Surg. 2016;49:234-41.

3. Sorin Group. Perceval sutureless aortic heart valve instruction for use. 2015; HVV_LS-850-0002 Rev X03. Available at: http://www.accessdata.fda.gov/ cdrh_docs/pdf15/P150011d.pdf.

4. Minh TH, Mazine A, Bouhout I, El-Hamamsy I, Carrier M, Bouchard D, et al. Expanding the indication for sutureless aortic valve replacement to patients with mitral disease. J Thorac Cardiovasc Surg. 2014;148:1354-9.

5. Folliguet T, Laborde F, Zannis K, Ghorayeb G, Haberich A, Shreshta M. Sutureless Perceval aortic valve replacement: results of two European centers. Ann Thorac Surg. 2012;93:1483-8. 